\title{
Impact of non-neoplastic vs intratumoural hepatitis B viral DNA and replication on hepatocellular carcinoma recurrence
}

\author{
Qin Wang ${ }^{1}$, Luan Lin ${ }^{2}$, Seungyeul Yoo ${ }^{2}$, Wenhui Wang ${ }^{2}$, Sima Blank ${ }^{1}$, M Isabel Fiel ${ }^{3}$, Hena Kadri ${ }^{1}$, Wei Luan ${ }^{1}$, \\ Leslie Warren ${ }^{1}$, Jun Zhu ${ }^{\star, 2}$ and Spiros $\mathrm{P}$ Hiotis ${ }^{*}, 1$ \\ ${ }^{1}$ Department of Surgery, Icahn School of Medicine at Mount Sinai, 5 East 98th Street, 12th Floor, Box 1259, New York, NY 10029, \\ USA; ${ }^{2}$ Department of Genetics and Genomic Sciences, Icahn School of Medicine at Mount Sinai, 1425 Madison Avenue, \\ New York, NY 10029, USA and ${ }^{3}$ Department of Pathology, Icahn School of Medicine at Mount Sinai, New York, NY 10029, USA
}

Background: This study aims to determine the impact of intracellular hepatitis B virus (HBV) DNA, covalently closed circular DNA (cccDNA) and viral replicative activity in both tumour and non-neoplastic liver on prognosis and to determine the relationship of viral replicative activity and Ishak fibrosis in predicting outcome following resection.

Methods: A total of 99 prospectively enrolled patients treated with primary liver resection for HBV-HCC are included. Intracellular HBV DNA and cccDNA were quantitated by real-time PCR. The RNA-sequencing (RNA-seq) was performed in a subset of 21 patients who had either minimal liver fibrosis (Ishak stages 0-2) or end-stage fibrosis (Ishak stage 6).

Results: Tumour tissue contained a lower cccDNA copy number compared with paired non-neoplastic liver, and larger tumours $(>3 \mathrm{~cm})$ had less cccDNA compared with small tumours $(\leqslant 3 \mathrm{~cm})$. High viral replicative activity in non-neoplastic liver was associated with higher $\mathrm{HCC}$ recurrence rate independent of Ishak fibrosis stage. Genes correlated with viral replicative activity in non-neoplastic liver (620 genes) were distinct from those associated with end-stage fibrosis (1226 genes). Genes associated with viral replicative activity were preferentially distributed in regions on chr3, chr16 and chr19.

Conclusions: Viral replicative activity in non-neoplastic liver is associated with HCC recurrence through mechanisms that are distinct from and independent of Ishak fibrosis stage.

Hepatitis B virus (HBV) is an enveloped DNA virus that primarily infects hepatocytes. In a mature virion, viral DNA is present in a relaxed circular form (rcDNA) that is partially double stranded. After entering the host cell, viral genome is transported into the nucleus, where rcDNA is converted into covalently closed circular DNA (cccDNA) (Levrero et al, 2009). The content of cccDNA, once formed, is stable in quiescent hepatocytes, and can be reduced by dilution through cell division, killing of infected cells or suppression by antiviral cytokines (Belloni et al, 2012).

Persistent HBV infection is a major risk factor for devel opment of HBV-associated hepatocellular carcinoma (HCC). Viral proteins, viral genome integration into the host genome, inflammation, oxidative stress and prolonged fibrotic responses associated with chronic HBV infection may all play important roles in hepatocarcinogenesis (Xu et al, 2010; Zhou et al, 2010; Arzumanyan et al, 2013). Our previous studies have shown that end-stage fibrosis (Ishak stage 6) is independently associated with poor overall survival and higher HCC recurrence rate (Wang et al, 2013 b, c). Moreover, our previous study using paraffin-embedded non-neoplastic liver tissue specimens from $111 \mathrm{HBV}-\mathrm{HCC}$ patients treated between 1991 and 2008 showed that viral replicative activity, as indicated by the proportion of cccDNA in total HBV DNA, correlated with necroinflammatory damage and Ishak fibrosis stage and that high viral replicative activity in the non-

*Correspondence: Professor J Zhu; E-mail: Jun.zhu@mssm.edu or Dr SP Hiotis; E-mail: spiros.hiotis@mountsinai.org 
neoplastic liver was associated with poor outcome for HBV-HCC patients (Wang et al, 2013c).

The goal of this study is to determine whether the impact of $\mathrm{HBV}$ viral replicative activity on outcome is mediated through mechanisms independent of or secondary to fibrosis. This report describes results from a prospective cohort of patients, completely distinct from the previous retrospective cohort. Only data generated from fresh tissue specimens, obtained from prospectively enrolled primary liver resection patients between 2008 and 2013, are included in this study. Intracellular HBV DNA and cccDNA and viral replicative activity (cccDNA/HBV DNA ratio) were measured using standardised qualitative PCR (Laras et al, 2006; Volz et al, 2007; Pollicino et al, 2011) and compared in 99 paired tumour and non-neoplastic liver tissue specimens of HBV-HCC patients. The impact of intracellular viral DNA and viral replication on clinical outcome following surgical resection with intent to cure is also determined.

\section{MATERIALS AND METHODS}

Patients, histopathologic assessment and follow-up. This is a prospective analysis of $99 \mathrm{HBV}-\mathrm{HCC}$ patients who underwent primary surgical resection with curative intent at the Mount Sinai Medical Center in New York between 2008 and 2013. Of these patients, $90 \%$ had documented therapy with antiviral drugs, and most had been treated for a short course of time preceding their HCC diagnosis. Majority of the patients received one type of antiviral (82\%), $17 \%$ received two types of antiviral and $1 \%$ received three types of antiviral treatment. Most commonly used antivirals were entecavir (39\%), tenofovir (34\%) and adefovir (23\%). The other antivirals such as telbivudine made up $4 \%$ of all antiviral treatment types. Preoperative serum HBV DNA was determined from the medical record. In our institutional clinical lab serum HBV DNA levels are quantitated using the COBAS AmpliPrep-COBAS TaqMan HBV test with a reported range of $23-2 \times 10^{8} \mathrm{IU} \mathrm{ml}^{-1}$ (Faria et al, 2008). Median follow-up of the survivors is 30 months.

Liver resection specimens were assessed by a single liver pathologist. The degree of hepatic fibrosis in non-neoplastic liver tissue was scored using the modified Ishak method (stages 0-6) as follows: stage 0 (normal liver); stage 1 (fibrosis expansion of a few portal tracts); stage 2 (fibrosis of all portal tracts); stage 3 (fibrous expansion of most portal areas with occasional portal to portal bridging); stage 4 (fibrous expansion of portal areas with marked bridging); stage 5 (marked bridging with occasional nodules); and stage 6 (established cirrhosis with the tissue entirely composed of nodules) (Goodman, 2007; Wang et al, 2013b). Patients with multiple tumours were not excluded from this study. Histologic activity index (HAI, scored from 0 to 18) representing necroinflammatory grade, tumour differentiation and vascular invasion were assessed by the pathologist.

Detailed methodology of patient diagnosis and follow-up is included in Supplementary Materials and Methods.

Quantitative intrahepatic HBV DNA and cccDNA measurements. The HBV DNA and cccDNA were amplified from genomic DNA using the QIAamp DNA extraction kit as previously described (Qiagen, Valencia, CA, USA) (Kuang et al, 2010; Schrader and Iredale, 2011; Wang et al, 2013c). Detailed methodology is included in Supplementary Materials and Methods.

Gene expression analysis using RNA-seq. Gene expression was evaluated in a subset of 21 patients using RNA-seq technology in non-neoplastic liver (Supplementary Table 3). All patients with tumour size smaller than $5 \mathrm{~cm}$, either with minimal liver fibrosis (Ishak stages $0-2, n=10$ ) or with probable or definite cirrhosis (Ishak stage $6, n=11$ ), were included. Total RNA (1-3 $\mu$ g per sample) was submitted to the Mount Sinai Genomics Core Facility for quality control analysis. Detailed methodology for RNA-seq is included in Supplementary Materials and Methods.

The expression level of genes was estimated by RPKM (reads per kilobase of exon model per million mapped reads) that is normalised to the length of a gene and total mapped reads in one sample. Genes that correlated with viral replicative activity were identified using Spearman's correlation test. At $P<0.01,620$ genes correlated with viral replicative activity, corresponding to the false discovery rate (FDR) of 0.2 based on the $\mathrm{BH}$ method (Wang et al, 2011). The functional enrichment of these 620 genes was then analysed by searching the Gene Ontology (GO) database and by comparing with gene sets in the Molecular Signatures Database (Subramanian et al, 2005). The distribution of these genes on chromosomes was determined by dividing the genome into $30 \mathrm{Mb}$ bins and counting the number of genes in each bin. The enrichment level was evaluated using Fisher's exact test by comparing the distribution of signature genes and overall genes.

Genes that were differentially expressed in Ishak stages $0-2$ vs Ishak stage 6 were similarly identified and compared with those that correlated with viral replicative activity.

Statistical analysis. All statistical analyses were performed using SPSS 19 (Intel, Santa Clara, CA, USA) and SAS 9.2 (SAS Institute, Cary, NC, USA) software. Detailed methodology is included in Supplementary Materials and Methods.

Study approval. Institutional review board (IRB) approval of all aspects of the research was obtained before study initiation. Written informed consent was obtained for every patient enrolled in this study. The study protocol conformed to the ethical guidelines of the 1975 Declaration of Helsinki, as reflected by the appropriate institutional review committee.

\section{RESULTS}

Characterisation of HBV viral load in tumour and paired nonneoplastic liver. This study included $99 \mathrm{HBV}-\mathrm{HCC}$ patients who were prospectively enrolled (Supplementary Table 1). Mean age was 55 years, and the majority of patients were male $(83 \%)$ and of Asian race (86\%). Mean tumour size was $4.2 \mathrm{~cm}$, and median tumour size was $3.0 \mathrm{~cm}$. Mean HAI was 3.8 , and mean Ishak stage was 4.2 .

Intracellular $\mathrm{HBV}$ DNA and cccDNA and viral replicative activity as indicated by the cccDNA/HBV DNA ratio were compared in tumour and paired non-neoplastic liver specimens $(n=99$, Table 1$)$. The HBV DNA correlated with cccDNA copy number in both tumour and non-neoplastic liver (Spearman's correlation coefficient: $r=0.63$ and $r=0.56$, respectively, $P<0.001)$. Compared with paired non-neoplastic liver, tumour tissue was more likely to have undetectable HBV DNA. Tumour tissue had lower cccDNA copy number than paired non-neoplastic liver tissue, and was more likely to have undetectable cccDNA (38\% in tumour vs $6 \%$ in non-neoplastic liver). In the samples that had detectable cccDNA, viral replicative activity in tumour correlated with that in non-neoplastic liver (Spearman's correlation $r=0.53, P<0.001)$.

The PCR-based assay to quantitate HBV viral load amplifies all sequences flanked by the specific primers that include integrated viral sequence and viral genome. A subset of samples were treated with plasmid-safe DNase to assess the impact of viral integration. After DNase treatment, albumin copy number decreased $>100$-fold, from $6607 \times 10^{3}$ copies to $46 \times 10^{3}$ copies, indicating the effectiveness of DNase treatment. The HBV DNA copy number in the same set of sample decreased from $22 \times 10^{3}$ copies to $3 \times 10^{3}$ copies, reflecting a seven-fold decrease. The copy number of cccDNA decreased from $1 \times 10^{3}$ copies to $0.3 \times 10^{3}$ copies, 
reflecting a three-fold decrease. Therefore, the PCR-based assay amplified both viral genome and integrated viral DNA.

Higher cccDNA copy number in smaller tumours when compared with larger tumours. Early tumours (smaller than median, $\leqslant 3 \mathrm{~cm}$ ) had higher cccDNA copy number per cell within the tumour when compared with larger tumours $(>3 \mathrm{~cm})$ (median: 0.0004 copy per cell, $n=57$, vs 0 copy per cell, $n=42$ ) (Figure 1A). In contrast, the cccDNA copy number in the nonneoplastic liver of patients with small $v s$ large tumours did not differ. In patients with small tumours, the cccDNA copy number did not differ between tumour and paired non-neoplastic liver, whereas in patients with larger tumours, the cccDNA copy in tumour was significantly lower than the paired non-neoplastic liver. Similar findings were observed for intrahepatic HBV DNA (Figure 1B). Small tumour and large tumours did not differ in viral replicative activity (median cccDNA/HBV DNA ratio: 0.09 in small tumour $v s 0.06$ in larger tumours).

Copy number of cccDNA within tumour was not different when compared according to tumour differentiation, vascular invasion or $\alpha$-fetoprotein production (data not shown).

Intrahepatic viral load and viral activity based on serum HBV DNA and HBeAg status. Of the patients in this study, $90 \%$ had documented therapy with antiviral drugs. Despite antiviral therapy, $49 \%$ of patients had detectable serum HBV DNA at the time of their liver resection, and 96\% had detectable HBV DNA in liver tissue. The HBV DNA, cccDNA and cccDNA/HBV DNA ratio in tumour or non-neoplastic liver did not differ between patients with undetectable $v s$ those with detectable serum HBV DNA (Supplementary Table 2).

The HBeAg status immediately before surgery was available for 67 patients $(76 \%$ were $\mathrm{HBeAg}$ negative, whereas $24 \%$ were $\mathrm{HBeAg}$ positive) (Supplementary Table 2). The cccDNA/HBV DNA ratio in non-neoplastic liver was significantly higher in $\mathrm{HBeAg-negative}$ patients, indicating lower replicative activity in the liver tissue, whereas all other viral features were not different. Moreover, the proportion of $\mathrm{HBeAg}$-negative patients was significantly higher in patients with low HBV replicative activity in non-neoplastic liver compared with those with high HBV replicative activity (93\% vs $62 \%, P=0.004$ ) (Supplementary Table 3 ). Therefore, only HBV replicative activity in non-neoplastic liver correlated with serum HBeAg status.

Impact of viral replicative activity in tumour and non-neoplastic liver on patient survival and HCC recurrence. The 5-year overall survival rate of the 99 patients was $72 \%$, and HCC recurrence rate was $44 \%$ by Kaplan-Meier analysis. Most recurrence occurred within 24 months of surgical resection. The impact of total intracellular HBV DNA, cccDNA and replicative activity in both tumour and non-neoplastic liver tissue on outcome was examined by comparing groups according

Table 1. Comparison of HBV DNA viral load and replicative activity within tumour and paired non-neoplastic liver ( $n=99$ pairs)

\begin{tabular}{|c|c|c|c|}
\hline & Tumour & Non-neoplastic liver & $P$-value \\
\hline \multicolumn{4}{|c|}{ HBV DNA (copies per cell) } \\
\hline $\begin{array}{l}\text { Detectable } \\
\text { Median (range) }\end{array}$ & $\begin{array}{l}86 / 99(86 \%) \\
0.04(0-4441.2)\end{array}$ & $\begin{array}{l}96 / 99(96 \%) \\
0.07(0-17.5)\end{array}$ & $\begin{array}{l}0.02 \\
0.7\end{array}$ \\
\hline \multicolumn{4}{|c|}{ cccDNA (copies per cell) } \\
\hline $\begin{array}{l}\text { Detectable } \\
\text { Median (range) }\end{array}$ & $\begin{array}{c}61 / 99(62 \%) \\
0.00004(0-2.7)\end{array}$ & $\begin{array}{l}93 / 99(94 \%) \\
0.008(0-0.8)\end{array}$ & $\begin{array}{c}<0.001 \\
0.03\end{array}$ \\
\hline \multicolumn{4}{|c|}{ Replicative activity cccDNA/HBV DNA ratio } \\
\hline Median (range) & $0.008(0-24.6)$ & $0.1(0-9.7)$ & 0.002 \\
\hline
\end{tabular}

A

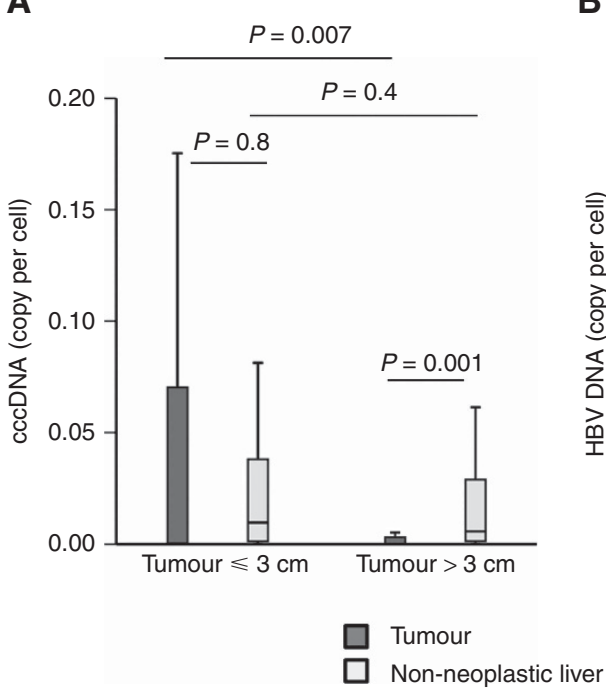

B

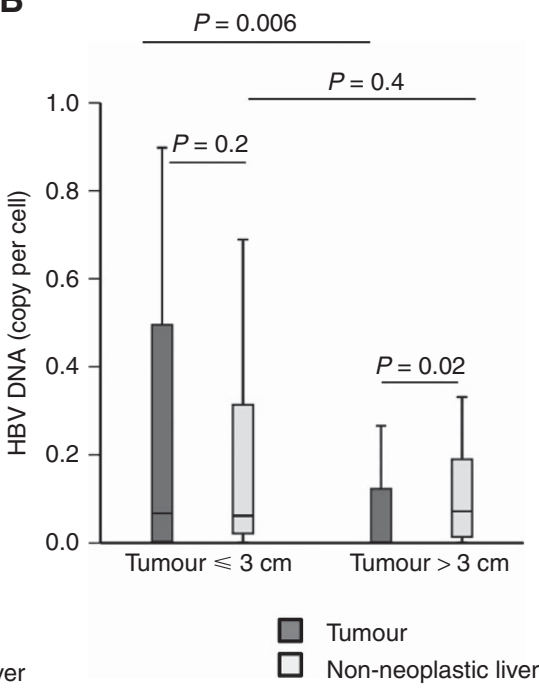

Figure 1. Small HCC $(\leqslant 3 \mathrm{~cm})$ had higher cccDNA and HBV DNA copy number when compared with large $\mathrm{HCC}$ ( $>3 \mathrm{~cm})$. Box plot showing cccDNA copy per cell (A) or HBV DNA copy per cell (B) within the tumour (filled bars) or non-neoplastic liver (open bars) of patients with small HCC $(\leqslant 3 \mathrm{~cm})$ or large $\mathrm{HCC}(>3 \mathrm{~cm})$. 
to median cutoff values (Table 2 and Figure $2 \mathrm{~A}$ and $\mathrm{B}$ ). None of the viral characteristics in tumour or non-neoplastic liver was associated with overall survival.
Viral replicative activity within the non-neoplastic liver was associated with HCC recurrence rate (Table 2 and Figure 2A and B). High viral replicative activity (lower cccDNA/HBV DNA ratio) in

Table 2. The impact of viral characteristics in both tumour and non-neoplastic liver tissue (NT) on overall survival and HCC recurrence

\begin{tabular}{|c|c|c|c|c|}
\hline & \multicolumn{2}{|c|}{ Overall survival } & \multicolumn{2}{|c|}{ Recurrence } \\
\hline & Death events ( 5 years) & $P^{a}$ & Recurrence events ( 5 years) & $P$-value ${ }^{a}$ \\
\hline \multicolumn{5}{|l|}{ HBV DNA } \\
\hline $\begin{array}{l}\text { NT } \\
\text { Low }(n=49) \\
\text { High }(n=50)\end{array}$ & $\begin{array}{l}7 \\
9\end{array}$ & 0.5 & $\begin{array}{l}16 \\
19\end{array}$ & 0.7 \\
\hline \multicolumn{5}{|l|}{ cccDNA } \\
\hline $\begin{array}{l}\text { Tumour } \\
\text { Low }(n=49) \\
\text { High }(n=50)\end{array}$ & $\begin{array}{l}9 \\
7\end{array}$ & 0.4 & $\begin{array}{l}16 \\
19\end{array}$ & 0.2 \\
\hline $\begin{array}{l}\text { NT } \\
\text { Low }(n=49) \\
\text { High }(n=50)\end{array}$ & $\begin{array}{l}8 \\
8 \\
\end{array}$ & 0.4 & $\begin{array}{l}20 \\
15\end{array}$ & 0.8 \\
\hline $\begin{array}{l}\text { NT } \\
\text { Low }(n=48) \\
\text { High }(n=48)\end{array}$ & $\begin{array}{r}6 \\
10\end{array}$ & 0.1 & $\begin{array}{l}12 \\
21\end{array}$ & 0.04 \\
\hline $\begin{array}{l}\text { Abbreviations: } \mathrm{cccl} \\
\text { listed in the table, } \\
\mathrm{a}_{P \text {-value determine }} \\
\mathrm{b}_{\text {Groups were sep }} \\
{ }^{c_{\text {Replicative activity }}}\end{array}$ & $\begin{array}{l}\text { ed circular DNA; HBV = hepatitis } \\
\text { determined by Kaplan-Meier anal } \\
\text { analysis and Wilcoxon test or log-r } \\
\text { median cutoff values. } \\
\text { e ccCDNA/HBV DNA ratio. This re }\end{array}$ & $\begin{array}{l}\text { pato } \\
n \text { tes }\end{array}$ & $\begin{array}{l}\text { oma; NT }=\text { non-neoplastic liver tissue. Nu } \\
\text { test. } P<0.05 \text { were indicated in bold. } \\
\text { ith undetectable HBV DNA. }\end{array}$ & or recurrence events ar \\
\hline
\end{tabular}

A
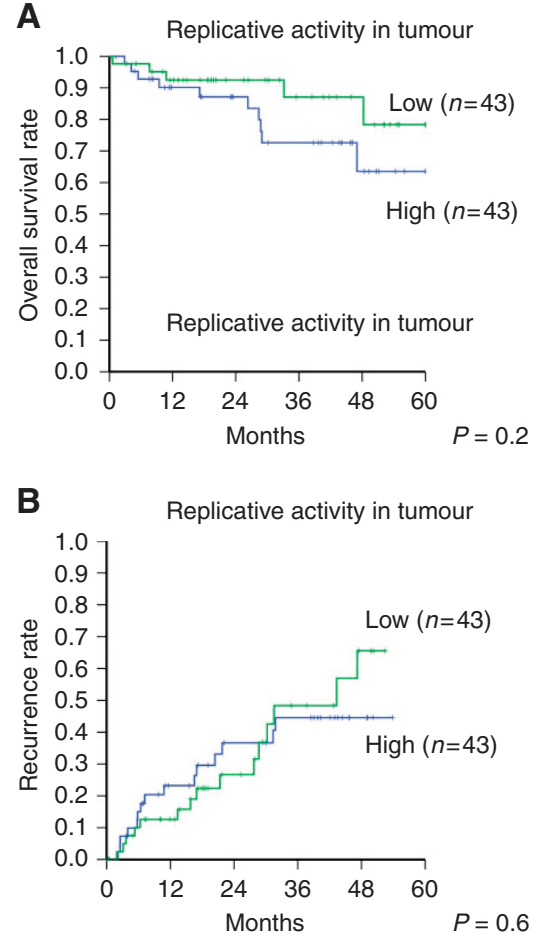

Replicative activity in non-neoplastic liver

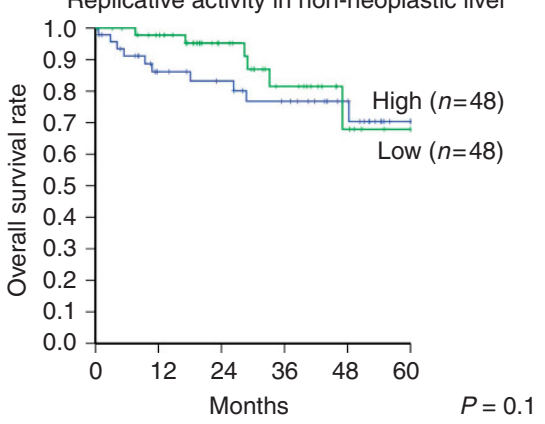

Replicative activity in non-neoplastic liver

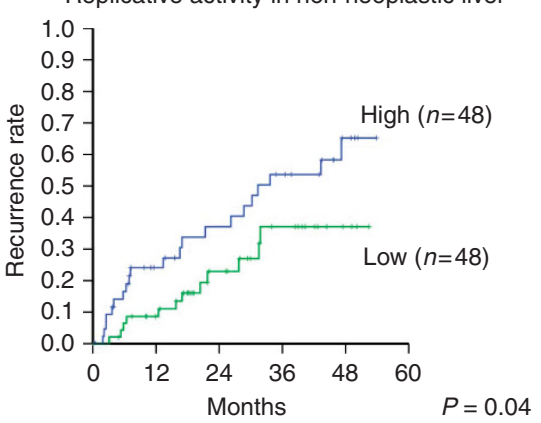

Figure 2. The impact of viral replicative activity (cccDNA/HBV DNA ratio) at the time of liver resection on overall survival and recurrence rate following resection. Overall survival $(\mathbf{A})$ and recurrence rate $(\mathbf{B})$ stratified by the median cutoff of cccDNA/HBV DNA ratio within tumour or nonneoplastic liver was constructed using Kaplan-Meier method and compared using log-rank test or Wilcoxon test. 
the non-neoplastic liver was associated with higher recurrence rate (Figure 2B). High viral replicative activity (lower cccDNA/HBV DNA ratio) in the non-neoplastic liver was also associated with greater HAI (4.1 vs 3.4, $P=0.04)$ and higher fibrosis stage (4.7 vs 3.9, $P=0.01$ ), consistent with our previous studies in the retrospective cohort (Supplementary Table 3). When adding fibrosis stage as a covariant, viral replicative activity in nonneoplastic liver was still significantly associated with HCC recurrence by Cox proportional hazards regression (HR: 2.1 (1.0-4.5), $P=0.04)$, suggesting that viral replicative activity contributes to HCC recurrence independent of fibrosis.

Gene expression associated with viral replicative activity in nonneoplastic liver. We hypothesise that viral replicative activity and fibrosis in non-neoplastic liver may influence different biological pathways implicated in HCC recurrence. The gene signatures associated with viral replicative activity or liver fibrosis in nonneoplastic liver were then analysed in a subgroup of 21 patients using RNA-seq (Supplementary Table 4). Of these patients, 10 had minimal fibrosis (Ishak stages $0-2$ ), whereas 11 had end-stage fibrosis (Ishak stage 6). All 21 patients had HCC $<5 \mathrm{~cm}$.

There were 620 of genes whose expression levels correlated with viral replicative activity (Supplementary Table 5), noted as viral replicative activity-associated (VRAA) genes. The VRAA genes were not enriched for any GO terms and only enriched for the signature 'GINESTIER_BREAST_CANCER_ZNF217_AMPLIFIED_DN' in MSigDB (3.6-fold enrichment, $P=2.9 \times 10^{-11}$ ), a set of downregulated genes when ZNF217 locus at 20q13 is amplified in breast cancer (Ginestier et al, 2006). The ZNF217 is a zinc-finger protein that is often amplified at 20q13 in breast cancer (Krig et al, 2010). Zinc-finger proteins as a whole were enriched in the VRAA gene set (1.6-fold enrichment, $P=0.01)$.

There were 1226 genes that were differentially expressed in non-neoplastic liver of Ishak fibrosis stages 0-2 vs Ishak stage 6 (Supplementary Table 6). These genes were functionally enriched for three signatures related to liver cancer (Supplementary Table 7). Genes associated with Ishak fibrosis stage showed little overlap with genes in the VRAA gene set, and only 26 common genes were identified (Supplementary Table 8).
Whether these differentially expressed genes are enriched in any chromosomal locations was also determined. The VRAA genes were enriched in regions on chr19, chr16 and chr3 $(P<0.01)$ (Figure $3 \mathrm{~A})$. Fibrosis-associated genes were enriched in regions on chr19, chr17 and chr6 $(P<0.01)$ (Figure 3B).

Viral genotype and variants in tumour and non-neoplastic liver tissue. Viral genotype and variants were also determined from RNA-seq analysis in the 21 pairs of tumour and non-neoplastic liver tissue specimens (Supplementary Table 4). The paired tumour and non-neoplastic liver tissue specimens had the same genotype and the same subvariant. Genotypes $\mathrm{C}$ and $\mathrm{B}$ were most prevalent, $56 \%$ and $39 \%$, respectively, and only $5 \%$ had genotype A. Most patients with end-stage fibrosis (78\%) had viral genotype C, whereas most patients with early-stage fibrosis had viral genotype B (56\%).

The assembled HBV viral contigs in each sample were aligned to each other to determine whether there are multiple viral variants in each sample. All samples contained contigs with with less than 1 single-nucleotide polymorphism (SNP) per kb HBV viral sequence, with the exception of contigs in one sample where two HBV viral contigs were different at 17 SNPs per $\mathrm{kb}(1.7 \%$ sequence difference). These results suggest that all samples contain a single $\mathrm{HBV}$ variant (sequence difference $<4 \%$ ). Among all assembled viral genomes, only one pair of samples contained HBV genomes that were mapped to drug-resistant strains (https://hbvdb.ibcp.fr/ HBVdb/HBVdbResistance).

\section{DISCUSSION}

Although viral replicative activity in non-neoplastic liver correlated with the severity of liver fibrosis, RNA-seq analysis demonstrated that very distinct gene signatures were associated with viral replicative activity or liver cirrhosis. These genes were enriched for different biological functions and distributed on different regions along the human chromosome. These results therefore support the hypothesis that viral replicative activity and fibrosis in
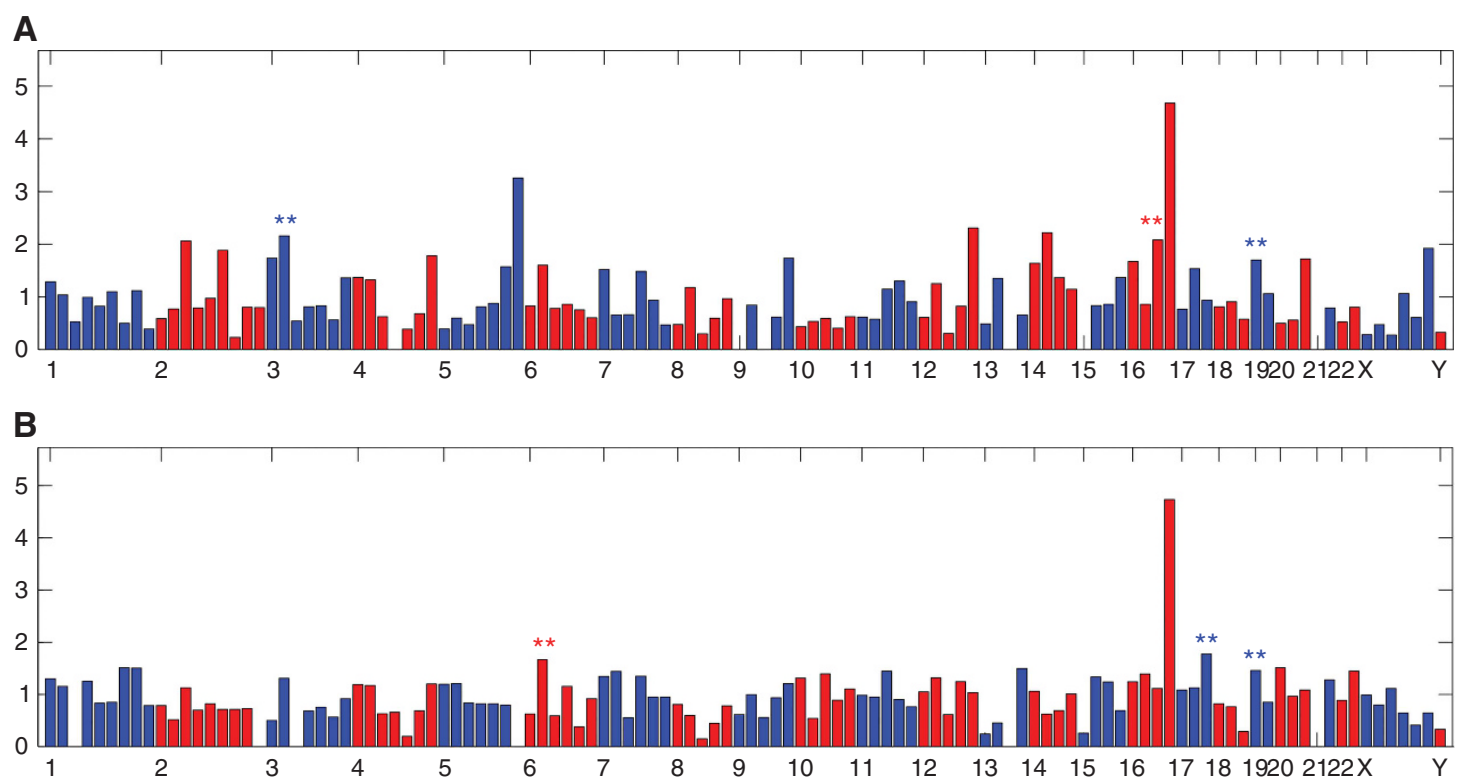

Figure 3. Distribution of genes associated with viral replicative activity or Ishak fibrosis stage along the chromosomes. The DNA sequences along human chromosomes were divided into a total of 152 bins (bin size $=30 \mathrm{Mb}$ ). Enrichment of genes associated with viral replicative activity (A) or Ishak fibrosis (B) that fall within each bin is evaluated by the fold changes in the number of genes that fall within each bin over the number of genes within each bin if it happens by chance. ${ }^{*}$ Significant enrichment with $P$-value of $<0.01$. 
non-neoplastic liver may influence different biological pathways implicated in HCC recurrence.

Viral replicative activity correlates with the expression of genes that showed a 3.6-fold enrichment for a set of downregulated genes when ZNF217 locus at $20 \mathrm{q} 13$ is amplified in breast cancer 'GINESTIER_BREAST_CANCER_ZNF217_AMPLIFIED_DN'. The ZNF217 is an oncogene and a transcription factor that is part of the corepressor of REST complex (Cowger et al, 2007). Binding of ZNF217 to the promoter region of one of its targets, p15 $5^{\text {ink } 4 \mathrm{~b}}$ (a cyclin-dependent kinase inhibitor and a tumour suppressor gene), leads to aberrant silencing of $\mathrm{p} 15^{\text {ink } 4 \mathrm{~b}}$ and cell immortalisation (Thillainadesan et al, 2012). Indeed, ZNF217 is found at the core of the $20 \mathrm{q} 13$ amplicon that is frequently amplified in breast cancer, ovarian cancer and prostate carcinoma (Rahman et al, 2012; Szczyrba et al, 2013; Bai et al, 2014). Overexpression of ZNF217 is associated with poor prognosis in breast cancer and ovarian cancer (Rahman et al, 2012; Vendrell et al, 2012). The functional importance of ZNF217 is poorly understood in HCC, although chromosomal aberrations including DNA copy number gains of 20q are often observed in HCC (Patil et al, 2005). The observations that VRAA genes are enriched for copy number variation $(\mathrm{CNV})$-regulated genes but not for any GO biological processes suggest that VRAA genes may not result from biological perturbations, but rather from variations in genomic structure.

Tumour, when compared with non-neoplastic liver, had lower cccDNA copy per cell. This may occur as a result of dilution by division of tumour cells. In a urokinase-type plasminogen activator /severe combined immunodeficiency (SCID) mouse model, hepatocyte proliferation induces loss of cccDNA (Lutgehetmann et al, 2010). Studies in the duck model showed that anti-viral therapy induces a greater cccDNA reduction in animals with higher hepatocyte proliferation (Addison et al, 2002). Our data also suggest a role for cell division in regulating cccDNA copy numbers, as small tumours were found to contain higher cccDNA copy number than large tumours; and in patients with small tumours, intra-tumoural cccDNA copy number did not differ from that in paired non-neoplastic liver.

Our observation of lower cccDNA levels within tumour is consistent with a recent report of $42 \mathrm{HBV}-\mathrm{HCC}$ patients (Wang et al, 2013a), but differs from an earlier report of $25 \mathrm{HBV}$-HCC patients showing higher cccDNA copy number in tumour than non-neoplastic liver (Wong et al, 2006). The reasons for the differences with the earlier study are unclear, although our study quantified HBV DNA and cccDNA copy number per cell by measuring and normalising to albumin copy numbers in all samples, rather than by calculating cell numbers based on the estimation of $6.667 \mathrm{pg}$ genomic DNA per cell (Wong et al, 2006).

Our previous retrospective studies showed that viral replicative activity in the non-neoplastic liver is associated with poor overall survival, but not recurrence-free survival, following surgical resection. This current study differs from that study in several ways. This current study includes surgical resection patients from 2008 to 2013, whereas the previous study included patients from 1991 to 2008. Several differences should also be noted such as smaller tumour size in the current study $(4.3 \pm 3.6$ vs $7.3 \pm 5.0 \mathrm{~cm})$. In this current study, viral DNA was measured using fresh surgical resection specimens, whereas in the previous study, viral DNA was measured using DNA isolated from archived paraffin blocks. Despite all of these differences, this current study confirms our previous observations that viral replicative activity correlates with HAI and Ishak stage, and that high viral replicative activity is associated with poor outcome. As these patients are continuing to be followed, the impact of viral replicative activity on recurrencefree survival and overall survival will be further evaluated.

In summary, this study presents a direct comparison of intracellular HBV DNA, cccDNA and viral replicative activity within tumour and non-neoplastic liver. The data showed that high replicative activity within the non-neoplastic liver is associated with higher HCC recurrence rate through mechanisms that are distinct from and independent of Ishak fibrosis stage.

\section{ACKNOWLEDGEMENTS}

This study was funded by NIH R21CA170722 (to JZ).

\section{CONFLICT OF INTEREST}

The authors declare no conflict of interest.

\section{REFERENCES}

Addison WR, Walters KA, Wong WW, Wilson JS, Madej D, Jewell LD, Tyrrell DL (2002) Half-life of the duck hepatitis B virus covalently closed circular DNA pool in vivo following inhibition of viral replication. J Virol 76(12): 6356-6363.

Arzumanyan A, HMGPV Reis, Feitelson MA (2013) Pathogenic mechanisms in HBV- and HCV-associated hepatocellular carcinoma. Nat Rev Cancer 13(2): 123-135.

Bai W-D, Ye X-M, Zhang M-Y, Zhu H-Y, Xi W-J, Huang X, Zhao J, Gu B, Zheng G-X, Yang A-G, Jia L-T (2014) MiR-200c suppresses TGF- $\beta$ signaling and counteracts trastuzumab resistance and metastasis by targeting ZNF217 and ZEB1 in breast cancer. Int J Cancer 135(6): $1356-1368$.

Belloni L, Allweiss L, Guerrieri F, Pediconi N, Volz T, Pollicino T, Petersen J, Raimondo G, Dandri M, Levrero M (2012) IFN- $\alpha$ inhibits HBV transcription and replication in cell culture and in humanized mice by targeting the epigenetic regulation of the nuclear cccDNA minichromosome. J Clin Invest 122(2): 529-537.

Cowger JJ, Zhao Q, Isovic M, Torchia J (2007) Biochemical characterization of the zinc-finger protein 217 transcriptional repressor complex: identification of a ZNF217 consensus recognition sequence. Oncogene 26(23): 3378-3386

Faria LC, Gigou M, Roque-Afonso AM, Sebagh M, Roche B, Fallot G, Ferrari TCA, Guettier C, Dussaix E, Castaing D, Brechot C, Samuel D (2008) Hepatocellular carcinoma is associated with an increased risk of hepatitis B virus recurrence after liver transplantation. Gastroenterology 134(7): 1890-1899.

Ginestier C, Cervera N, Finetti P, Esteyries S, Esterni B, Adelaide J, Xerri L, Viens P, Jacquemier J, Charafe-Jauffret E, Chaffanet M, Birnbaum D, Bertucci F (2006) Prognosis and gene expression profiling of 20q13amplified breast cancers. Clin Cancer Res 12(15): 4533-4544.

Goodman ZD (2007) Grading and staging systems for inflammation and fibrosis in chronic liver diseases. J Hepatol 47(4): 598-607.

Krig SR, Miller JK, Frietze S, Beckett LA, Neve RM, Farnham PJ, Yaswen PI, Sweeney CA (2010) ZNF217, a candidate breast cancer oncogene amplified at 20q13, regulates expression of the ErbB3 receptor tyrosine kinase in breast cancer cells. Oncogene 29(40): 5500-5510.

Kuang DM, Peng C, Zhao Q, Wu Y, Chen MS, Zheng L (2010) Activated monocytes in peritumoral stroma of hepatocellular carcinoma promote expansion of memory T helper 17 cells. Hepatology 51(1): 154-164.

Laras A, Koskinas J, Dimou E, Kostamena A, Hadziyannis SJ (2006) Intrahepatic levels and replicative activity of covalently closed circular hepatitis B virus DNA in chronically infected patients. Hepatology 44(3): 694-702.

Levrero M, Pollicino T, Petersen J, Belloni L, Raimondo G, Dandri M (2009) Control of cccDNA function in hepatitis B virus infection. J Hepatol 51(3): 581-592.

Lutgehetmann M, Volz T, Köpke A, Broja T, Tigges E, Lohse AW, Fuchs E, Murray JM, Petersen J, Dandri M (2010) In vivo proliferation of hepadnavirus-infected hepatocytes induces loss of covalently closed circular DNA in mice. Hepatology 52(1): 16-24.

Patil MA, Gutgemann I, Zhang J, Ho C, Cheung ST, Ginzinger D, Li R, Dykema KJ, So S, Fan ST, Kakar S, Furge KA, Buttner R, Chen X (2005) Array-based comparative genomic hybridization reveals recurrent chromosomal aberrations and Jab1 as a potential target for 8q gain in hepatocellular carcinoma. Carcinogenesis 26(12): 2050-2057. 
Pollicino T, Raffa G, Santantonio T, Gaeta GB, Iannello G, Alibrandi A, Squadrito G, Cacciola I, Calvi C, Colucci G, Levrero M, Raimondo G (2011) Replicative and transcriptional activities of hepatitis B virus in patients coinfected with hepatitis B and hepatitis delta viruses. J Virol 85(1): 432-439.

Rahman MT, NakayAma K, Rahman M, Katagiri H, Katagiri A, Ishibashi T, Ishikawa M, Iida K, Nakayama N, Otsuki Y, Nakayama S, Miyazaki K (2012) Gene amplification of ZNF217 located at chr20q13.2 is associated with lymph node metastasis in ovarian clear cell carcinoma. Anticancer Res 32(8): 3091-3095.

Schrader J, Iredale JP (2011) The inflammatory microenvironment of HCC the plot becomes complex. J Hepatol 54(5): 853-855.

Subramanian A, Tamayo P, Mootha VK, Mukherjee S, Ebert BL, Gillette MA, Paulovich A, Pomeroy SL, Golub TR, Lander ES, Mesirov JP (2005) Gene set enrichment analysis: a knowledge-based approach for interpreting genome-wide expression profiles. Proc Natl Acad Sci USA 102(43): $15545-15550$.

Szczyrba J, Nolte E, Hart M, Döll C, Wach S, Taubert H, Keck B, Kremmer E, Stöhr R, Hartmann A, Wieland W, Wullich B, Grässer FA (2013) Identification of ZNF217, hnRNP-K, VEGF-A and IPO7 as targets for microRNAs that are downregulated in prostate carcinoma. Int J Cancer 132(4): 775-784.

Thillainadesan G, Chitilian JM, Isovic M, Ablack JN, Mymryk JS, Tini M, Torchia J (2012) TGF- $\beta$-dependent active demethylation and expression of the p15ink4b tumor suppressor are impaired by the ZNF217/CoREST complex. Mol Cell 46(5): 636-649.

Vendrell JA, Thollet A, Nguyen NT, Ghayad SE, Vinot S, Bièche I, Grisard E, Josserand V, Coll J-L, Roux P, Corbo L, Treilleux I, Rimokh R, Cohen PA (2012) ZNF217 is a marker of poor prognosis in breast cancer that drives epithelial-mesenchymal transition and invasion. Cancer Res 72(14): 3593-3606

Volz T, Lutgehetmann M, Wachtler P, Jacob A, Quaas A, Murray JM, Dandri M, Petersen J (2007) Impaired intrahepatic hepatitis B virus productivity contributes to low viremia in most HBeAg-negative patients. Gastroenterology 133(3): 843-852.
Wang M, Qiu N, Lu S, Xiu D, Yu J, Wang Xt Lu F, Li T, Liu X, Zhuang H (2013a) Serum hepatitis B surface antigen is correlated with intrahepatic total HBV DNA and cccDNA in treatment-naïve patients with chronic hepatitis B but not in patients with HBV related hepatocellular carcinoma. J Med Virol 85(2): 219-227.

Wang Q, Fiel MI, Blank S, Luan W, Kadri H, Kim KW, Manizate F, Rosenblatt AG, Labow DM, Schwartz ME, Hiotis SP (2013b) Impact of liver fibrosis on prognosis following liver resection for hepatitis B-associated hepatocellular carcinoma. Br J Cancer 109: 573-581.

Wang Q, Fiel MI, Luan W, Blank S, Kadri H, Kim KW, Hiotis SP (2013c) Impact of intrahepatic hepatitis B DNA and covalently closed circular DNA on survival after hepatectomy in $\mathrm{HBV}$-associated hepatocellular carcinoma patients. Ann Surg Oncol 20: 3761-3770.

Wang Q, Luan W, Goz V, Burakoff SJ, Hiotis SP (2011) Non-invasive in vivo imaging for liver tumour progression using an orthotopic hepatocellular carcinoma model in immunocompetent mice. Liver Int 31(8): 1200-1208.

Wong DK-H, Yuen M-F, Poon RT-P, Yuen JC-H, Fung J, Lai C-L (2006) Quantification of hepatitis B virus covalently closed circular DNA in patients with hepatocellular carcinoma. J Hepatol 45(4): 553-559.

Xu J, Yun X, Jiang J, Wei Y, Wu Y, Zhang W, Liu Y, Wang W, Wen Y, Gu J (2010) Hepatitis B virus X protein blunts senescence-like growth arrest of human hepatocellular carcinoma by reducing Notch1 cleavage. Hepatology 52(1): 142-154.

Zhou Y, Wang S, Ma J-W, Lei Z, Zhu H-F, Lei P, Yang Z-S, Zhang B, Yao X-X, Shi C, Sun L-F, Wu X-W, Ning Q, Shen G-X, Huang B (2010) Hepatitis $\mathrm{B}$ virus protein $\mathrm{X}$-induced expression of the $\mathrm{CXC}$ chemokine IP-10 is mediated through activation of NF-kappaB and increases migration of leukocytes. J Biol Chem 285(16): 12159-12168.

This work is published under the standard license to publish agreement. After 12 months the work will become freely available and the license terms will switch to a Creative Commons AttributionNonCommercial-Share Alike 4.0 Unported License.

Supplementary Information accompanies this paper on British Journal of Cancer website (http://www.nature.com/bjc) 